\title{
THE CHANGING SHAPE OF SCOTLAND'S DIGITAL DIVIDE
}

\author{
Ruth Wilson ${ }^{1}$, Jonathan Hopkins ${ }^{2}$
}

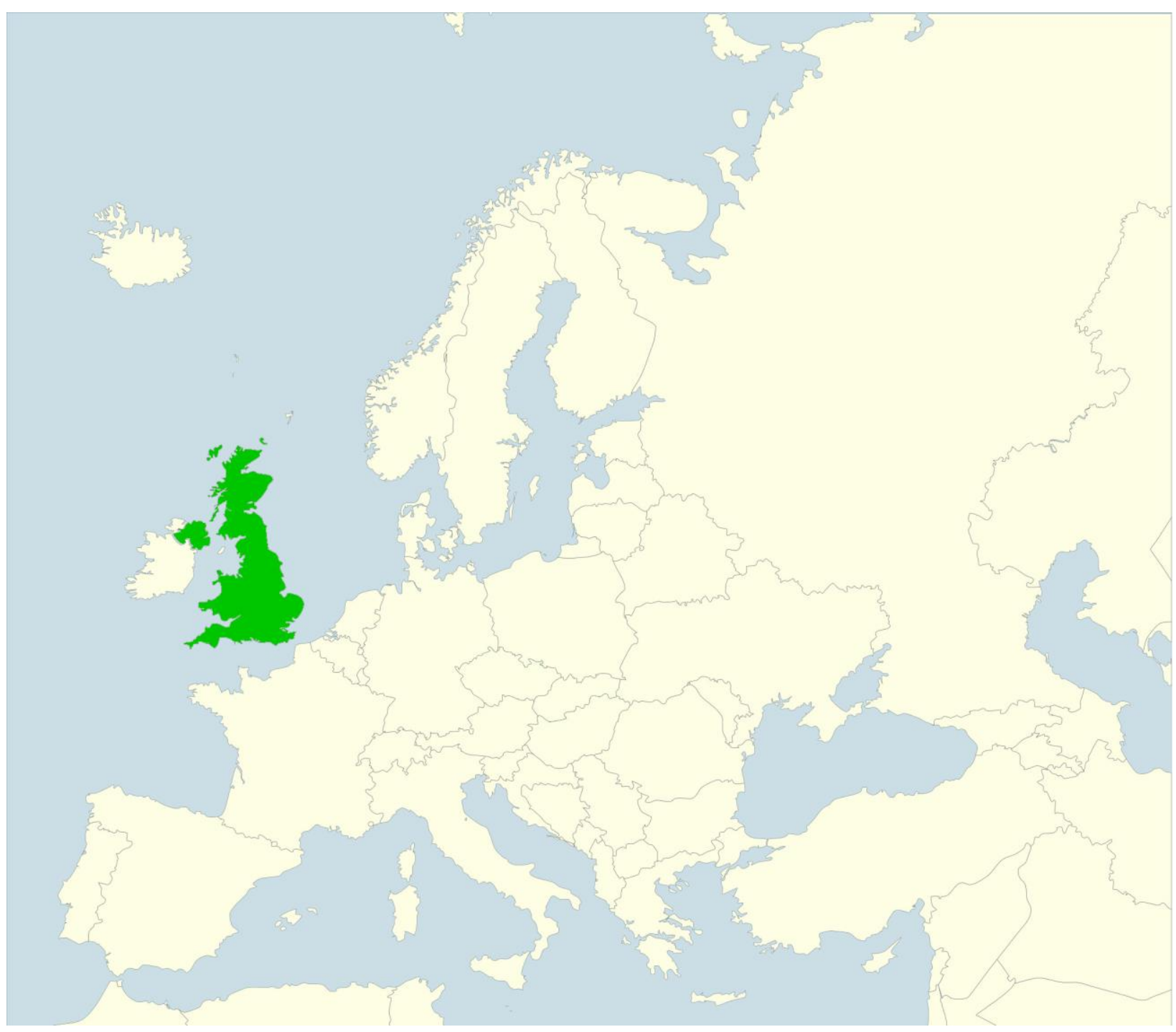

1 Ruth Wilson, PhD., the James Hutton Institute Aberdeen, United Kingdom; e-mail: ruth.wilson@hutton.ac.uk; ORCID ID: 0000-0002-5096-3054

2 Dr. Jonathan Hopkins, the James Hutton Institute Aberdeen, United Kingdom; e-mail: jonathan.hopkins@hutton.ac.uk; ORCID ID: 0000-0002-3845-7677 
Abstract: The challenges of reaching rural areas with the latest digital technologies are well documented, resulting in a longstanding urban-rural digital divide in many countries. In 2016, Scotland embarked on one of the most ambitious infrastructure projects in Europe when it committed to bringing superfast broadband to all of its citizens by 2021. In this paper, we take stock of recent progress towards this goal by applying the framework of the "Sparsely Populated Area". While previous work has highlighted that Scotland's digital divide is shrinking, application of this new framework reveals inequalities that traditional urban-rural classifications mask. We show that, while the number of digital "not spots" has fallen in recent years, many of those remaining are concentrated in a region that faces particular vulnerabilities in terms of service delivery and population decline. Digital inequalities introduce a further challenge to this region in addressing its potential as a viable and attractive place to live and work.

Keywords: digital, digital divide, broadband, Scotland, remote, rural, sparsely populated area

\section{Introduction}

Like many European nations, Scotland faces an ongoing challenge to provide access for all of its homes and businesses to state-of-the-art digital technology. From the rollout of the first digital subscriber lines in 2000 to the first superfast fibre in 2008, the nation's broadband network has spread quickly to encompass $95 \%$ of premises (Ofcom, 2018b). However, market forces alone have not been strong enough to supply the same technology to the remaining population, much of which is dispersed across remote, mountainous and island areas.

This has resulted in a longstanding and well-documented urban-rural digital divide in Scotland (Philip et al., 2015; Skerratt et al., 2010). While broadband technology has become increasingly ubiquitous in urban centres, enabling new ways of living, learning, working and playing, the technology has been slow to roll out to rural areas, despite growing recognition of the potential benefits to geographically dispersed and remote communities (Wilson et al., 2018). Recognised advantages to people living in such areas include: the potential to overcome aspects of their geographical remoteness by accessing key services, such as education and healthcare, online; the possibility for remote working for companies based in urban centres, particularly where there is a shortage of employment opportunities locally; the ability for rural businesses to advertise and sell to markets elsewhere in the country and internationally; and the opportunity to make and maintain social connections with family and friends located elsewhere. In this sense, high speed broadband can be seen as an infrastructural technology, which, when in place, can enable access to many benefits.

Over the past twenty years, a range of government policies has attempted to address this issue, culminating in 2016 when the Scottish Government announced its ambition to reach 100\% of premises with superfast broadband by the end of 2021 (Scottish Government, 2017a). Under the "Reaching 100\%" (R100) Programme, the Scottish Government is procuring additional infrastructure in areas where superfast speeds of greater than $30 \mathrm{Mbps}$ are not currently available, in order to achieve its commitment to "Realising Scotland's full potential in a digital world: A Digital Strategy for Scotland" (Scottish Government, 2017b).

We begin this paper by summarising theoretical understandings of the digital divide in the context of digital disadvantage and exclusion (section 2). Next, we outline how the Scottish Government has tried to address the divide over the years, with varying success, through an evolving series of policies (section 3). In section 4, we examine the progression of superfast fibre across Scotland between 2015 and 2018, using the framework of the "Sparsely Populated Area" (SPA) to analyse findings (Copus and Hopkins, 2018). Section 5 reflects on what this progress means for residents, businesses and the future prosperity of the SPA, drawing on interviews with stakeholders and community representatives. In section 6 we discuss 
the broader implications of our findings and section 7 draws out transferable lessons for other European countries facing similar challenges.

In this paper, we examine progress to date and show that the digital divide is changing shape but that there is now a concentration of digital "not spots" in some of the country's most vulnerable regions. This has particular implications for the capacity of these areas to address concerns around depopulation and delivery of services and to harness the potential for digital connectivity to overcome many longstanding disadvantages of living "on the edge".

\section{The urban-rural digital divide}

At a purely technological level, differences in digital connectivity influence the volume of data that can be downloaded and consumed, with data consumption rising as broadband speeds have increased (Ofcom, 2012, p. 1). But they also have consequences that go far beyond the ability to download large files. In Castells' understanding of the "network society", the NorthSouth social and political demarcations that once split the globe have been redrawn by states of inclusion in and exclusion from digital networks. For communities that are not connected, this has implications for their capacity to harness economic prosperity, knowledge and power: "In a global economy, and in a network society where most things that matter are dependent on these Internet-based networks, to be switched off is to be sentenced to marginality" (Castells, 2001a, p. 277).

Others have described the digital divide variously as a hierarchy (Selwyn, 2004) and a rainbow (Clement and Shade, 2000), emphasising that the divide is not so much dichotomous but rather is characterised by varying degrees of connectivity and therefore of inclusion and exclusion. Van Dijk envisages a continuum rather than a cleavage with the "information elite" at one end and at the other end the "digitally illiterate or truly excluded", with the majority of the population falling in the middle of the spectrum with some form of access and varying degrees of use (van Dijk, 2005, p. 13). The result is that inequalities are relative rather than absolute, a question of having more or less access than others in the network and the differentiated access to resources that this brings with it.

Moreover, because digital technology is embedded in everyday life, exclusion in the network society is multi-dimensional and can occur across political, economic, cultural and social spheres. As van Dijk puts it, the inequalities become "structural":

Structural inequality appears when, on the one hand, an "information elite" strengthens its position, while, on the other hand, those groups already living on the margins of society become excluded from communications in society because these are practiced in media they do not possess or control. The differences become structural when the positions people occupy in networks and other media determine whether they have any influence on decisions made in several fields of society. (van Dijk, 2005, p. 17).

In this view, those with no or inferior access will become second or third-class citizens, or "no citizens at all" (van Dijk, 2005, p. 17).

While the urban-rural divide in Scotland is no longer absolute in terms of access to digital infrastructure, differences in connection speed and mobile connectivity persist, with people living in the country's rural areas generally having slower access to digital infrastructure than people living in towns and cities in the rest of the country and indeed in many cities in the rest of the developed world (Philip et al., 2015). Although digital infrastructure has improved across the country as a whole, improvements in rural connectivity have always been outpaced by further enhancements in urban connectivity, and the prevailing pattern has remained one in which rural residents have persistently inferior access. In the language of van Dijk (2005), this affects the ability of rural residents, businesses and communities to participate fully in the network society, with patchier and slower access meaning that they stay on the edge of the network that is the economic and social fabric of contemporary society.

Warren (2007) talks about the danger of this becoming a "digital vicious cycle", with digital exclusion reinforcing social disadvantage such that the rural minority, on the wrong side of the digital divide, becomes progressively disadvantaged as citizens elsewhere enjoy increasing 
advantages associated with digital economic and social transactions: "As governments, agencies, corporations and individuals increasingly rely on electronic means for the transmission and storage of information, the advantages of access to the Internet increase" (ibid., p. 376).

Recent research in the UK has focused on exactly what digital disadvantage means for rural communities. Philip et al. (2015) identify an urban "digital fast lane" and a rural "digital slow lane" and note that the ADSL connections provided to many rural premises cannot support the kind of always-on, next-generation Internet use described by Dutton and Blank (2011), in which members of the same household use different digital devices for different tasks simultaneously, a behaviour that is becoming the norm in cities. Philip et al. (2015) posit that, as the general public's expectations of digital engagement rise, this could negatively affect inward migration to rural areas, as people become reluctant to lose capabilities and habits that have become embedded in their everyday lives.

Ashmore et al. (2015) frame the UK urban-rural digital divide in terms of resilience and find that high-speed Internet access has highly individualised outcomes, enabling new patterns of behaviour that give people greater control over important aspects of their lives, and potential for rural community outcomes in the form of economic growth and demographic diversification. Wallace et al. (2017) highlight that digital connectivity can have different outcomes - individual and community-focused - in different rural places, while Wilson et al. (2015) emphasise the role of place identity in how rural residents negotiate online connections.

Rather than digital connectivity overcoming problems associated with geographical remoteness (Cairncross, 1997), redrawing the world map in favour of rural regions, the distribution of technological infrastructure reflects and reinforces the patterns of urbanisation already in place. As such, rural regions are arguably being marginalised in the same digitally networked social structure that was promised to overcome their geographic peripherality. It is important that such areas have access to high speed broadband so that longstanding inequalities are addressed and new, digital inequalities, do not become entrenched, effectively improving the potential of the country's geographically peripheral regions as places to live and work.

\section{Digital policies in Scotland}

Policymakers have traditionally put great emphasis on these positive outcomes for rural residents and communities. Throughout Europe, digital connectivity has been seen as a solution to deepening rural decline: "[The utopian discourse] was very attractive to rural policy-makers at all levels who were grappling with the problems of rural regions representing something of a panacea" (Talbot and Gillespie, 2008, p. 156). In Scotland, the rollout of digital technology has been a key consideration for the Scottish Government for the past twenty years, with coverage of rural areas a concern from the outset. The government has recognised both that digital technology has the potential to address the challenges of providing public services to sparsely populated regions and to encourage new forms of economic development, and that market forces alone would be insufficient to supply the latest technology to the hardest to reach places.

The rollout of digital technology has been a key consideration for the Scottish Government for the past twenty years, with coverage of rural areas a concern from the outset. In 2001, the then Scottish Executive launched an early example of digital policy in the form of "Connecting Scotland: Our Broadband Future" (Scottish Executive, 2001). This aimed to make "always on" connectivity more affordable and pervasive, and recognised that market forces alone may not provide the infrastructure needed to make this happen. The strategy advocated an approach of "aggregated procurement" to improve the telecommunications infrastructure across the public sector, including upgraded broadband capacity for schools, hospitals, libraries and council offices, which, it was thought, would generate demand and make further investment in rural areas more attractive for the private sector. The approach was implemented through a $£ 90$ million investment in two "Pathfinder" projects - one in the Highlands and Islands and one in the south of Scotland - to make infrastructure improvements across the public sector with the intention that rural homes, businesses and communities would also benefit by making use of the same technological backbone. A subsequent review of Pathfinder found that, while 
the aggregated approach had been successful in reaching widely across the public sector in Scotland with a reliable service and high connection speeds, the wider benefits to rural homes and businesses had not been felt and would require greater emphasis in future programmes (Scottish Government, 2011).

In the mid-2000s, as ADSL broadband became ubiquitous in many urban areas, so the scale and implications of the urban-rural digital divide became more apparent (Scottish Executive, 2006). In 2005, under the Scottish Executive's "Broadband for Scotland's Rural and Remote Areas" initiative, BT enabled exchanges in twenty local authority areas to deliver ADSL broadband to households and businesses that would not otherwise have received the service. At the launch of the initiative, the Enterprise Minister recognised the importance of digital technology to rural life: "We cannot allow remote and rural communities to fall behind simply because they cannot access this vital technology that can make a positive difference to many aspects of our lives" (Broadband for Scotland, 2005). To supplement the upgrading of exchanges, Avanti Communications won a $£ 3.3$ million contract to deliver affordable broadband, via satellite and $\mathrm{WiFi}$, to homes and businesses that could not otherwise access it, eventually supplying solutions to almost 4,000 premises in Scotland and leading to a substantial increase in access and use.

By 2010, basic broadband coverage in Scotland had reached $99.6 \%$, outstripping most of Europe (Skerratt et al., 2010). However, while households in rural Scotland were more likely to have Internet access at home, they were less likely to have high speed connections, with the remotest areas experiencing the poorest speeds (ibid.). With cities enjoying substantially faster broadband speeds than rural villages, the 2010 Rural Scotland In Focus report suggested that a new digital divide was opening up, based on speed, with implications for the capabilities of individuals, communities and businesses in rural areas (ibid.). In the same year, Reform Scotland recommended that the Scottish Government take account of Scotland's extensive rural landscape in its digital strategy (Reform Scotland, 2010), while the Royal Society of Edinburgh called for nationwide access to broadband speeds of at least $16 \mathrm{Mb} / \mathrm{s}$ by 2015 , and the development of a fibre infrastructure that will reach all of Scotland's communities (Royal Society of Edinburgh, 2010). The Scottish Government addressed these recommendations in its "Digital Ambition" for next generation broadband to be available to all by 2020, with significant progress by 2015 (Scottish Government, 2010). In its report, the government acknowledged that "rural areas will suffer if left to the market alone" and that "many people who could benefit most from digital technology are least able to access and use it", citing the benefits and challenges of submitting applications for agricultural subsidies online as an example of how the potential for digital technology is not being fully realised for rural communities (ibid.). To supplement the UK Government's rural market testing project in the Highlands and Islands, the Scottish Government also announced that it would make available $€ 1$ million of European funding under the LEADER programme for small-scale projects in rural communities to improve coverage and speeds. The ambition was taken forward in the Government's strategy for "Scotland's Digital Future" (Scottish Government, 2011), which set out the way forward for digital service delivery, digital economy, digital participation and digital connectivity, and led to the establishment of a ministerial sub-committee to take responsibility for implementing the strategy and project boards to focus on broadband infrastructure and digital uptake.

In 2014, the Scottish Government and BT agreed a public-private partnership, with contracts reaching $£ 442$ million, to roll out fibre broadband to areas that would not have been covered by commercial rollout alone, bringing coverage across Scotland to 95\% by 31 December 2017, with targets also stipulated for all local authority areas. During the same period, Highlands and Islands Enterprise administered the Community Broadband Scotland scheme across the whole of Scotland, aimed at the most hard-to-reach communities in remote and rural Scotland, to support community-led solutions through funding and advice, although this was found to be less successful than anticipated, with just 13 projects of the 63 funded successfully providing superfast speeds to 1,936 premises (Audit Scotland, 2018).

In May 2016, the Scottish Government announced that it would push its ambition beyond the scope of the Digital Scotland Superfast Broadband Scheme through a $£ 600$ million investment in the "Reaching 100\%" (R100) programme. This aims to bring superfast broadband 
(speeds greater than 30Mbps) to every home and business in Scotland by the end of December 2021 , at an estimated average cost of $£ 4,000$ for each of the 147,000 premises it expects to cover. In its review of progress, Audit Scotland notes that further investment may be needed to reach all premises and that delivering on the R100 ambition by December 2021 will be difficult (Audit Scotland, 2018). The Scottish Government is looking at options such as using mobile, wireless and satellite technologies to reach the "final few", but Audit Scotland warns that these solutions can be more expensive for consumers, less reliable than fibre, and may not provide "future proofing" as technology and connectivity continue to evolve.

\section{Scotland's changing digital landscape}

To determine progress so far towards the Scottish Government's R100 ambition, we applied a definition of Scotland's "Sparsely Populated Area" (SPA) to an analysis of superfast broadband data. This allows us to understand the effects not just of rurality but also of sparsity on the rollout of the technology, providing a unique view of Scotland's changing digital divide.

This was achieved in two steps. First, we drew on Ofcom data regarding the percentage of postcodes in Scotland able to access superfast broadband between 2015 and 2018 (Ofcom, 2015; Ofcom, 2016; Ofcom, 2017; Ofcom, 2018a); Appendix 1 contains further information on these data sources, which are available as OpenData. By mapping postcodes to "data zones" (small areas often used in Scotland's official statistics), we developed an indicator to represent the extent of full superfast coverage, i.e. the percentage of postcodes in each data zone where all premises had superfast broadband available.

Figures 1 and 2 illustrate the extent of full superfast coverage in 2015 and 2018 respectively. They show a clear nationwide increase in superfast coverage, with the number of "not spot" data zones falling from 654 in 2015 to 52 in 2018, and the number of data zones with full superfast coverage rising from $21.9 \%$ in 2015 to $54.2 \%$ in 2018 . Notably, the total area covered by these $54.2 \%$ of data zones (dark green shading) is very small, due to the high population density in these areas. On the other hand, areas of lower coverage in 2018 still cover a considerable chunk of Scotland, due to the large geographical mass of these units in rural areas with a low population density. 


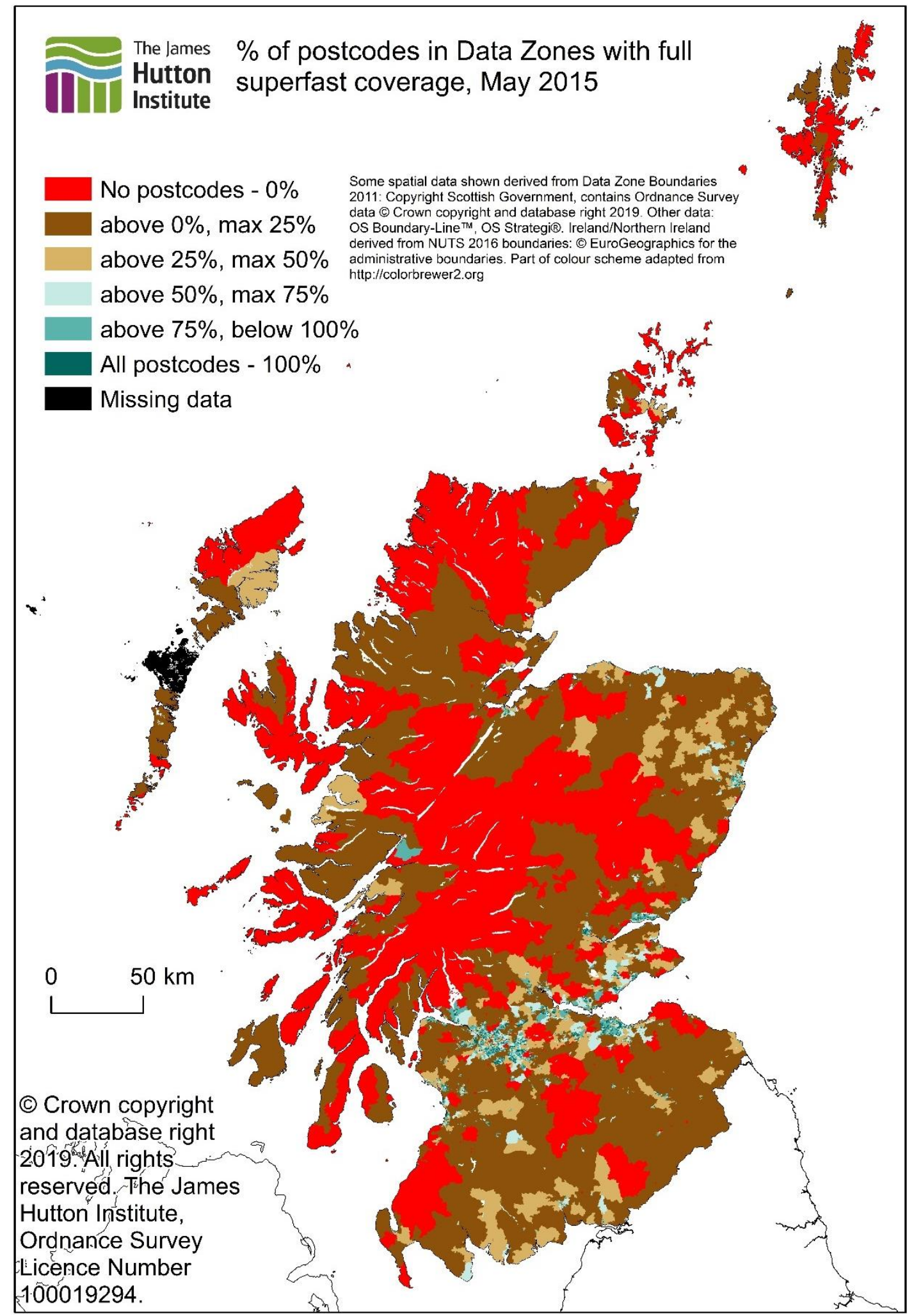

Fig 1. Extent of full superfast coverage, May 2015. 


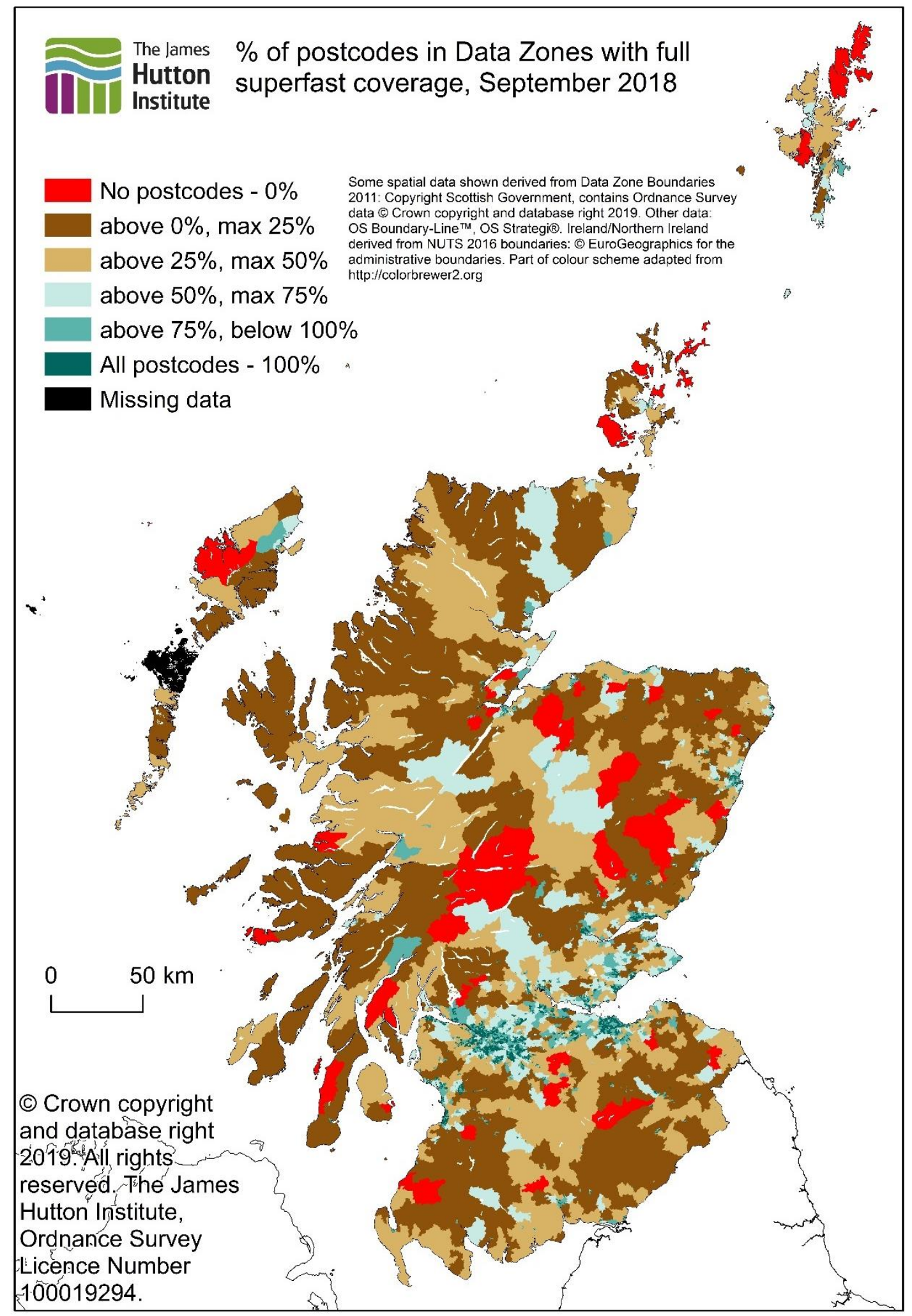

Fig 2. Extent of full superfast coverage, September 2018. 
Second, we classified data zones by combining two geographical typologies:

1. The Scottish Government Urban Rural Classification, which provides a standard definition of rural areas in Scotland (Scottish Government, 2014); and

2. For greater focus on the effects of sparsity, Copus and Hopkins (2017) definition of Scotland's "Sparsely Populated Area" (SPA). This builds on earlier work in Sweden (Gløersen et al., 2006) and measures a combination of population density, dispersion of settlements and travel distance to other people and, as such, arguably better reflects the challenges faced by less populated parts of Scotland than simple measures of density, rurality or remoteness alone (Copus and Hopkins, 2017). Specifically, Scotland's SPA is defined as locations in rural areas and small towns from which it is not possible to access 10,000 people (equivalent to an urban area) within 30 minutes' travel (Copus and Hopkins, 2017).

The combined classification comprised six categories:

- Large Urban Areas (settlements with a population of at least 125,000 people)

- Other Urban Areas (settlements with a population of 10,000 to 124,999)

- Small Town not in SPA (settlements of 3,000 to 9,999 people and from which it is possible to access 10,000 people within 30 minutes' travel)

- Small Town in SPA (settlements of 3,000 to 9,999 people and from which it is not possible to access 10,000 people within 30 minutes' travel)

- Rural not in SPA (settlements with a population below 3,000 and from which it is possible to access 10,000 people within 30 minutes' travel)

- Rural SPA (settlements with a population below 3,000 and from which it is not possible to access 10,000 people within 30 minutes' travel)

This classification was applied to data zones that had no superfast coverage in 2015 ("not spots") and we calculated the average change in extent of full superfast coverage by 2018 . Findings are presented in Table 1. Of the 2015 not spots, those in urban areas and small towns typically showed a considerable increase in coverage, with rural areas experiencing a smaller average increase. Within rural areas, not spots in the SPA had a smaller increase (Mdn: 34.67pp) than those than those outwith the SPA (Mdn: 61.41pp); this difference was found to be significant $(\mathrm{W}=20,105, p<0.001, r=-0.23)$. However, there was no significant difference between small town data zones inside and outside the SPA $(\mathrm{W}=882.5, p=0.651)$.

Tab 1. Regional comparison: average change in the extent of full superfast coverage, May 2015 - September 2018.

\begin{tabular}{|l|c|c|}
\hline & \multicolumn{2}{|c|}{$\begin{array}{c}\text { Data zones where no postcodes (0\%) had full } \\
\text { superfast access in May 2015 }\end{array}$} \\
\hline Region & Median & $\mathbf{n}$ \\
\hline Large Urban Area: Urban & 90.91 & 34 \\
\hline Other Urban Area: Urban & 81.08 & 59 \\
\hline Small Town: not in SPA & 95.45 & 159 \\
\hline Small Town: SPA & 94.80 & 12 \\
\hline Rural: not in SPA & 61.41 & 278 \\
\hline Rural: SPA & 34.67 & 112 \\
\hline
\end{tabular}

Medians (percentage points) to two decimal places.

In short, the geography of Scotland's digital divide has changed dramatically over the four-year analysis period, with not-spot areas shrinking considerably. Coverage has improved across all geographical classifications, but significantly less so in the rural SPA. Small towns in the SPA have, however, improved with small towns elsewhere. In other words, many of the most demographically and economically fragile parts of the country, which could benefit the most from superfast broadband, are not yet within reach of the new digital infrastructure. 


\section{Experiences of change in the Sparsely Populated Area}

Arguably, the pattern of superfast rollout we have identified above, from the most populated areas to small towns and accessible rural areas, and finally to the hardest to reach, is to be expected; moreover, progress is ongoing with the aim of covering all areas by the end of 2021. However, the implications of the changing shape of Scotland's digital divide should not be understated. First, it is not clear how or when the most challenging parts of the SPA will be connected and whether the technology will be as fast, as robust or as future-proofed as that available elsewhere (Audit Scotland, 2018). Second, as we discovered in interviews with stakeholders and community representatives from across the SPA, the effects of these changes in digital connectivity are felt keenly by residents and businesses, permeate to other areas of everyday life and work and can last long after the technology arrives.

Sixteen people participated in the interviews, which we conducted face-to-face and by telephone in late 2017 and early 2018. Interviews focused on the challenges of delivering services to the SPA and discussions ranged widely across a diverse set of services, from education and healthcare to transport and care homes, but broadband coverage was often raised as a current concern and a particular issue for the future prosperity of the area.

Positively, some participants observed that the fibre network had recently expanded in their region, or anticipated it doing so in the near future. Under the Digital Scotland Superfast Broadband (DSSB) programme, $400 \mathrm{~km}$ of subsea cables were laid between the mainland and islands, and between islands; this marine network under the Atlantic Ocean was completed in 2014, with island premises starting to benefit from fibre connectivity from the spring of 2015 (HIE, 2014). In mainland Scotland, the DSSB programme saw an additional 600,000 premises connected to superfast by the end of 2017. Stakeholders and community leaders from the Highlands and Islands region, in particular, commented that they could see the benefits of this investment and that many more premises had access to superfast broadband than would have been the case had there not been intervention through Highlands and Islands Enterprise and the Scottish Government. This was opening up new possibilities for individuals, businesses and communities and some "green shoots" of repopulation were mentioned by some community representatives, attributed directly to these developments.

However, reflecting the findings of our analysis of broadband data, the community representatives and some of the stakeholders we spoke to expressed concern that the rollout of superfast had been uneven, with some areas - usually in the SPA - remaining without adequate connections to date. While the DSSB scheme significantly extended the fibre backbone across the country to cover many more rural areas than it did before, the rollout of the "spider's web" of local access networks from the edges of the main network to exchanges and cabinets has often been implemented from the centre out, meaning that those places most distant from the backbone were connected last. Furthermore, there remains some uncertainty over exactly how and when premises and communities that are not within reach of fibre broadband will be connected. Community initiatives, many of which had funding from Community Broadband Scotland, were seen to require a great deal of volunteer time and effort, which some communities do not have at their disposal, as well as ongoing attention to maintain and upgrade the technology. In some places, the effort to implement a community broadband scheme had failed, and plans for local exchanges to be upgraded had also fallen through, resulting in communities feeling "worn down" and defeated. As we know from the foregoing analysis of superfast broadband data, the collective result of DSSB and community efforts is a reconfigured digital divide, in which many more rural communities now have access to superfast connectivity, but the most peripheral and sparsely populated areas remain superfast "not spots" (refer Fig 2).

The redrawn digital divide is being experienced as new divisions within and between islands, villages and townships, in which superfast connectivity has made some rural communities part of the global networked society, able to enjoy the same digital advantages as urban centres of Scotland, Europe and the developed world, while neighbouring communities remain excluded. While the number of communities without superfast broadband has shrunk, arguably the effects of the divide have grown stronger: those communities that are digitally excluded are in more of 
a minority than ever before, and are also much more keenly aware of what they are missing due to the proximity of their digitally connected neighbours. As one stakeholder put it:

Through the [fibre] rollout certain parts of our community now have superfast broadband but the problem with that system, although it's welcome, is you're actually increasing the inequality gap. In [community X] you can be connected up to seriously good broadband but five miles down the road or on the island of [community Y] you're on dialup. So by investing in that superfast technology you're increasing the gap.

There was a sense among some participants that the impact of the broadband gap is also increasing with the passing of time, and that this has particular consequences for children and young people who have grown up in areas where digital connectivity is not on a par with the rest of the country, since they do not have the habits or capabilities, and have not experienced the digital "way of life" that is commonplace among their peers. One island community representative expressed concern that, "As they get older and as our digital world develops, they're going to become more and more disadvantaged compared to their counterparts on the mainland. The school is great, they teach them how to use a computer, but it won't be as embedded". Indeed, the digital inequalities between neighbouring communities resulting from the recently expanded fibre network were felt so strongly by some stakeholders that they questioned whether an "outside in" approach to superfast rollout (from the most remote areas to the more central) might have been preferable, in order to prioritise the most vulnerable communities, or whether investing in the rollout of a minimum speed everywhere, rather than superfast in some places first, might have reduced the differential effects of the current situation and the impacts of this for residents and businesses.

Ironically, the Sparsely Populated Area of Scotland that our analysis has shown to be less digitally connected than urban and rural areas was felt to have the most to gain from superfast connectivity, with one community representative commenting that, "The people who this digital world can benefit the most are the people who are not getting it". In terms of running a business or being self-employed in the SPA, high-speed connectivity is essential to communicating with clients, colleagues and partners such that operating from a remote or peripheral geographical location is not a factor in the competitiveness of the business. This was felt by participants to apply to all businesses and not just those involved in digital content.

Stakeholders and community representatives also articulated a concern that opportunities are being lost to SPA residents and businesses through a lack of digital connectivity in terms of the provision of services. Service delivery to the SPA generally has a higher cost per head of population than more densely populated areas, even in rural areas outwith towns and cities. The per-pupil cost of a teacher in a school with a small roll, for example, is much higher than that of a larger school in a city. Current public sector budget cuts put additional strain on providing services to sparse populations, as the monetary savings to be made by reducing services can be substantial, and indeed the SPA has seen the closure in recent years of many banks, post offices, schools and health services (Wilson and Copus, 2018b). For some services, recent digital innovations mean that they can be delivered online, saving many of the costs associated with geographical distance and population sparsity, and providing a viable and sometimes enhanced alternative to their offline forms. Indeed, many of these innovations are emerging from rural areas, where the benefits are clear. For example, Comhairle nan Eilean Siar (Western Isles Council) have developed a platform called e-Sgoil (Electronic School) to deliver secondary education across a digital network with a view to improving the range of subjects on offer to pupils living in parts of Scotland where subject choices are constrained by the availability of teachers - this applies in particular to the SPA (Comhairle nan Eilean Siar, 2016). In healthcare, NHS Highland have launched an "NHS Near Me" Web app that allows patients to attend hospital consultations from their own homes through video calls using their computer or mobile phone; the service was introduced specifically to enable people living far from hospitals to attend appointments with doctors and other health care professionals without having to travel great distances (NHS Highland, 2018). However, as we know, in many parts of the SPA, where these services would arguably be valued most, it is not possible to enjoy their full potential because, as we have seen, superfast broadband is not yet available. Access to superfast connectivity is therefore increasingly key to accessing a host of other services. A lack 
of digital connectivity in parts of the SPA where physical access to the same set of services is already limited therefore has profound implications for residents and businesses, again deepening the effects of the digital divide.

The growing importance of high-speed broadband and its widespread implications for business functionality and participation in everyday life were recognised by stakeholders and community leaders, several of whom made explicit links between digital connectivity and net migration. One stakeholder noted that parts of their region where connectivity was strong had seen an increase in the population, describing it as a pull factor: "Why have some places been growing? People are drawn to the ability to work from home, become self-employed where there is internet connectivity, people in their 50 s, early 60 s working more flexibly". Conversely, other participants felt that the lack of broadband in their area deterred potential migrants who might want to live and work in a rural area, instead pushing them towards nearby places that do have broadband. One community leader spoke of recent cases in her area where this had happened: "We have families who have want to move into the area and had hoped to work from home and it's just not been possible for them because of the internet connectivity. [...] They might have moved to other areas [...] but they haven't moved [here]". With the population of the SPA projected to decline steeply in the next thirty years (Copus, 2018), it will be important to ensure that digital inequalities are addressed as quickly as possible and that the R100 challenge is fully met.

\section{Discussion}

The paper has identified a substantial decrease in the number of superfast "not spots" in Scotland, from 654 in 2015 to 52 in 2018 . This represents a significant step towards the Scottish Government's goal of reaching $100 \%$ of premises by the end of 2021 , bringing the benefits of digital connectivity to residents and businesses across the country.

Our analysis found that, while the border between digital hot spots and not spots was once and for a long time - loosely drawn along urban-rural boundaries, it has now shifted decisively towards the country's most sparsely populated areas, particularly those outwith small towns. Progress towards superfast coverage for not spots has been most rapid in cities and urban areas, then small towns, then rural areas outwith the SPA, with least movement in the rural SPA itself. These results reflect that access to superfast broadband is improving most quickly in places that were already, or are now, within reach of the fibre backbone. While progress across Scotland as a whole has been quick, many of the remaining areas with no coverage sit outside towns and cities and appear to be at or beyond the periphery of the fibre network.

With respect to the implications of these changes, it should first be noted that parts of the SPA have seen an improvement in coverage over the past four years, particularly in some small towns in which a proportion or even all premises have access to fibre broadband. This has benefits for residents and businesses in these areas, in that they are now able to participate fully in aspects of the network society, whether personal or professional, effectively overcoming some of the barriers presented by their sparsity and remoteness. At a community level, access to digital tools and services brings potential for economic and demographic growth and diversification, attracting more people to live and work there. The fact that 'notspots' in small town settlements in sparsely populated areas showed considerable improvement is likely to reflect the larger population (and market) compared with rural areas, and potentially demographic characteristics which favour higher demand for broadband (Grubesic, 2006 (discussing urban areas)). However, the drivers of increases in fast broadband availability in sparsely populated localities could be diverse, and include factors other than geographical remoteness and settlement size. The delivery of community broadband schemes has been seen to depend on multiple forms of capital, such as appropriate skills, leadership and networking, and financial resources (Wallace et al., 2015). Additionally, locations in the USA with superior broadband coverage to their surroundings (or 'islands of availability') were distributed evenly across large and smaller urban areas and rural regions (Grubesic, 2006). Although assessing the reasons for improvement in Scotland's 2015 'notspots' is beyond the scope of this paper, the methodology outlined creates new information and indicators which a) enables notspot locations to be pinpointed and b) identify rates of improvement in broadband 
quality (and spatial variations in these). This information could be used for designing further indepth case study research in this area, and (assuming that high quality, fine-grained broadband coverage data is available) could be replicated in other countries.

However, in many parts of the SPA progress has been slower than elsewhere in Scotland. These places are experiencing the same digital exclusion that they have been facing for some time, but in this paper we argue that the effects of their exclusion have intensified due to: 1) the increasing embeddedness of digital skills, behaviours and habits among the general population of Scotland, over the passage of time; 2) ongoing technological developments, for example in areas of service delivery, in which these communities cannot participate; 3 ) proximity to rural communities that do now have good access to superfast broadband, making those communities that are still without coverage very aware of the advantages they do not have; and 4) the increasing minority status of not-spot communities contributing to a sense of being "left behind" and of subsequent disempowerment.

The identified poor improvement in access to superfast broadband in sparse, rural areas poses a question of whether additional policy responses (beyond 'R100') are required, and if so, what form these should take. Scotland is a highly urbanised country with geographically large sparsely populated areas. In these cases, 'spatially blind' regional development policy responses would promote freer out-migration to economic centres (World Bank, 2009), with other areas theoretically benefitting through increased access to the opportunities promoted by economic agglomeration and improved services (Varga, 2017). However, putting aside evidence that most large cities in the UK are less productive than the country's average (Beatty and Fothergill, 2019), and the negative economic and social consequences of ignoring disadvantaged regions (Rodríguez-Pose, 2018), it is clear that migration to wealthier areas is not an option open to all people. In the UK, the rate of migration to different regions for jobs has broadly fallen from 2001 onwards: even among demographics perceived as particularly mobile (Clarke, 2017); a broader review suggests a fall in regional migration by the lower skilled (lammarino et al., 2017). Furthermore, it would be undesirable to increase the speed of rural depopulation in sparsely populated Scotland (Copus, 2018), an issue which is representative of rural trends in Europe (see ESPON EGTC, 2017). The advantages and disadvantages of population decline are debated, as some environmentalists support theoretical increases in quality of life, while negative economic impacts of lower tax incomes threatening public services and reduction in human capital are emphasised by others (van Dalen and Henkens, 2011); reduced agricultural activity in upland areas of Europe typically leads to environmental degradation (MacDonald et al., 2000). Taking a normative position that rural population loss is undesirable, investments in improved broadband connectivity in remote rural areas could form part of an appropriate place-based strategy (see: McCann and Rodríguez-Pose, 2011; Barca et al., 2012) based on the regional need identified in this paper. As this analysis shows that the established rural-urban divide has been realigned based on population sparsity, placebased interventions require fresh and creative approaches which move beyond policies which only consider rural connectivity more generally. The detailed spatial analysis within this paper, focusing on change over time and variations in improvement rates among 'notspots', can support spatial targeting, and further geographical research into notspots to learn more about their characteristics could also improve the quality of policy design. The latter should draw on other approaches from relevant studies: a recent analysis in Japan created a four-fold typology of technology use at the regional level, generating policy recommendations for each of these classifications (Nishida et al., 2014). An earlier study used small area-level data to define a 'broadband periphery' and 'islands of inequity' within the USA: regions with poor broadband access, but different degrees of local-level concentration or clustering of this characteristic, and comparisons with the 'broadband core' and 'islands of availability' (Grubesic, 2006).

The Scottish Government's stated aim of promoting broadband investment in remote rural areas before others (Scottish Government, 2017b: see Chapter 4) appears to be representative of the 'appropriate place-based strategy' noted above. It should be noted that non-fixed connections are likely to be needed: these are less desirable than fixed connections (Audit Scotland, 2018). Although the Government will rightly be criticised if it misses its 2021 deadline for full superfast broadband access (as is likely: Audit Scotland, 2018), they are not alone in 
this. The 'Europe 2020' goals include full superfast access by 2020, but most EU countries will not achieve this, with rural areas in particular falling short (European Court of Auditors, 2018). The lower likelihood of private investment in rural areas and evidence of inadequate public funding (Ibid: p7) shows close agreement with a reflection on broadband availability in the USA, that "...suggests that private firms can have difficulty in adequately providing public goods, such as communications infrastructure, in a spatially balanced manner" (Grubesic, 2006: 445). Logically, it is unlikely that full access to fast broadband will occur in Scotland, and elsewhere, without a significant increase in public investment. The Universal Service Obligation in the UK has established a legal right to request up to $£ 3,400$ for a "decent" connection (although below superfast speed) from March 2020 onwards (Hutton, 2019). The effect of this policy on not spots should be monitored.

The end point of our analysis (September 2018) is part-way along the journey towards the Scottish Government's goal of reaching $100 \%$ of premises by December 2021, and so we expect the boundary between hot spots and not spots to continue to shift, albeit reaching the final few will require more innovative technological solutions to supply superfast speeds to people and places that the fibre network cannot reach. Although the digital divide is fluid, it is nonetheless important to consider the ongoing impact of a longstanding lack of connectivity on local residents and businesses, both in terms of what they can accomplish practically, and in their sense of confidence in their community as a vibrant place to live and work. The stakeholders and community leaders we spoke to emphasised the impact on young people, in particular, in terms of their development of the digital skills and behaviours needed to thrive socially and economically as adults. Additionally, it is important to be aware of the new inequalities that are emerging between rural places as a result of the changing digital landscape, and of how this impacts the SPA in particular.

Our findings have implications for the wider context of our work on population change in sparsely populated areas, and the requirement to achieve a net migration of approximately $+1,000$ persons per year over the next thirty years to stabilise the SPA population (Copus, 2018). Digital connectivity is a key factor in retaining and attracting people of working age, enabling them to run businesses and work flexibly, and a prerequisite for the provision of many service innovations, with potential for public sector cost savings in a time of austerity. Continued rapid rollout of superfast broadband to remaining places with no or low coverage - with attention to the stability of connections, costs for consumers and future-proofing of the technology - is therefore vital to ensure that these most fragile of areas can finally take advantage of the technologies designed to overcome challenges of sparsity and play an equal part in the digitally networked structure that is the fabric of contemporary society.

\section{Final reflections}

Our findings from this analysis of progress in Scotland have implications for other European countries seeking to extend coverage of superfast broadband to their hardest-to-reach areas.

First, we have found it valuable to consider the challenges of digital coverage in terms of population sparsity, which presents particular logistical difficulties and high costs for delivering many services, including digital. Adopting the framework of the Sparsely Populated Area has thrown the effects of sparsity into sharp relief, revealing differences and inequalities across geographies that more traditional urban-rural classifications may mask. This has enabled us to look beyond the narrative of the urban-rural digital divide to focus on what has been happening in these most challenging of areas and the implications of recent technological change. The shift from a broad focus on rurality to the specific effects of sparsity adds considerable insight to publicly available data and could be adopted at similar scales throughout Europe.

Second, the approach taken to rolling out the fibre network across Scotland, under various Scottish Government programmes, has resulted in the quick spread of digital connectivity. However this has, at least in the short term, left out some of the country's most fragile communities, resulting in some new and some intensified inequalities between areas where neighbouring digital not spots have now become digital hot spots. It is easy to de-emphasise the negative impacts of these changes by focusing instead on areas of progress, or by 
disregarding them as temporary or fleeting, but our qualitative interviews have highlighted the importance of paying attention to the inequalities that new digital divisions can introduce and the intensity and longevity with which they can be felt. Indeed, it may be possible to manage rollout such that the risk of introducing new inequalities is minimised, for example following a region-by-region approach rather than being led by extensions to the technological infrastructure.

Third, in the race to increase coverage it is easy to forget that digital connectivity is not an end in itself but a means of achieving a range of everyday goals, such as accessing services, running businesses and maintaining social connections. It is therefore at least part of the solution to many other challenges facing sparsely populated areas and key to addressing demographic decline. As Warren (2007) notes, and as also emerges from our findings, digital exclusion has far-reaching consequences, just as the advantages of digital inclusion infuse many other areas of life. Particularly where the technology is of equivalent speed and quality to that available in the rest of the country, this can enable communities to retain existing residents and attract new ones, including young and economically active people. Investment in robust and future-proofed digital technology is, therefore, an investment in an infrastructure that could underpin many other improvements.

Finally, future analysis would benefit from the inclusion of data on mobile networks, which often form part of the solution for providing digital technology to premises in remote places. Although mobile broadband data has been published by Ofcom, this is only available for relatively large geographical areas (local authorities and constituencies) and therefore cannot be accurately matched to the postcode-level fixed broadband data. At the time of writing, more detailed datasets are not freely available, and the analysis presented here is driven by the availability of official, reusable high resolution data.

\section{Acknowledgements}

This paper was funded by the Rural and Environment Science and Analytical Services Division of the Scottish Government. The authors acknowledge funding under Work Package 3.4 of the 2011-2016 Strategic Research Programme. The views expressed in this paper are those of the authors and not those of the Scottish Government or RESAS. We would like to thank all participants in our interviews for their helpful comments. Thanks also to Andrew Copus for his helpful feedback on the paper.

\section{Academic references}

[1] Ashmore, F., Farrington, J. H. \& Skerratt, S. (2015). Superfast Broadband and Rural Community Resilience: Examining the Rural Need for Speed, Scottish Geographical Journal, 131(3-4), 265-278. DOI: 10.1080/14702541.2014.978808.

[2] Barca, F., McCann, P. \& Rodríguez-Pose, A. (2012). The case for regional development intervention: place-based versus place-neutral approaches. Journal of Regional Science, 52(1), 134-152. DOI: 10.1111/j.1467-9787.2011.00756.x.

[3] Beatty, C. \& Fothergill, S. (2019). Local productivity: The real differences across UK cities and regions [Project report]. Sheffield Hallam University.

[4] Cairncross, F. (1997). The death of distance: how the communications revolution will change our lives. London: Orion Business.

[5] Castells, M. (2000). The Rise of the Network Society (2 ${ }^{\text {nd }}$ Edition). Cambridge: Wiley Blackwell.

[6] Castells, M. (2001). The Internet Galaxy: Reflections on the Internet, Business and Society. New York: Oxford University Press.

[7] Clarke, S. (2017). Get A Move On? The decline in regional job-to-job moves and its impact on productivity and pay. London: Resolution Foundation. 
[8] Clement, A. \& Shade, L. (2000). The Access Rainbow: Conceptualising Universal Access to the Information/communication Infrastructure. In Gurstein, M., ed., Community Informatics (pp. 32-51). Hershey, PA: Idea Group Publishing.

[9] Copus, A. (2018). Demographic Projections for the Scottish Sparsely Populated Area (SPA) 2011-2046 [Working Paper]. Aberdeen: the James Hutton Institute.

[10] Copus, A. \& Hopkins, J. (2017). Outline Conceptual Framework and Definition of the Scottish Sparsely Populated Area (SPA) [Working Paper]. Aberdeen: the James Hutton Institute.

[11] Dutton, W. H. \& Blank, G. (2011). Next Generation Users: The Internet in Britain. Oxford: Oxford Internet Institute.

[12] Dutton, W. H. \& Blank, G. (2013). Cultures of the Internet: The Internet in Britain. Oxford: Oxford Internet Institute.

[13] Field, A., Miles, J. \& Field, Z. (2012) Discovering Statistics Using R. London: Sage.

[14] Gijón, C., Whalley, J. \& Anderson, G. (2016). Exploring the differences in broadband access speeds across Glasgow. Telematics and Informatics, 33(4), 1167-1178. DOI: 10.1016/j.tele.2015.11.003.

[15] Gløersen, E., Dubois, A., Copus, A. \& Schürmann, C. (2006). Northern peripheral, sparsely populated regions in the European Union [Nordregio Report]. Stockholm: NORDREGIO.

[16] Gravetter, F. J. \& Wallnau, L. B. (1992). Statistics for the Behavioral Sciences (3 ${ }^{\text {rd }}$ edition). St. Paul: West Publishing Company.

[17] Grubesic, T. H. (2006). A spatial taxonomy of broadband regions in the United States. Information Economics and Policy 18(4), 423-448. DOI: 10.1016/j.infoecopol.2006.05.001.

[18] Hopkins, J. and Copus, A. (2018). A Demographic Profile of the Scottish Sparsely Populated Area (SPA) 1991-2037. [Working Paper]. Aberdeen: the James Hutton Institute.

[19] Hutton, G. (2019). The Universal Service Obligation (USO) for Broadband. House of Commons Library [Briefing Paper Number CBP 8146]. London: House of Commons Library.

[20] lammarino, S., Rodríguez-Pose, A. \& Storper, M. (2017). Why Regional Development matters for Europe's Economic Future [Working Paper 07/2017]. Luxembourg: European Union.

[21] MacDonald, D., Crabtree, J. R., Wiesinger, G., Dax, T., Stamou, N., Fleury, P., Gutierrez Laxpita, J. \& Gibon, A. (2000). Agricultural abandonment in mountain areas of Europe: Environmental consequences and policy response. Journal of Environmental Management, 59(1), 47-69. DOI: 10.1006/jema.1999.0335.

[22] McCann, P. \& Rodríguez-Pose, A. (2011). Why and When Development Policy Should Be Place-Based. In OECD Regional Outlook 2011: Building Resilient Regions for Stronger Economies (pp. 203-213). Paris: OECD Publishing. DOI: 10.1787/9789264120983-en.

[23] Nishida, T., Pick, J. B. \& Sarkar, A. (2014). Japan's prefectural digital divide: A multivariate and spatial analysis. Telecommunications Policy, 38(11), 992-1010. DOI: 10.1016/j.telpol.2014.05.004.

[24] Philip, L. J., Cottrill, C. \& Farrington, J. (2015). "Two-speed" Scotland: Patterns and Implications of the Digital Divide in Contemporary Scotland. Scottish Geographical Journal 131(3-4), 148-170. DOI: 10.1080/14702541.2015.1067327.

[25] Philip, L. J., Cottrill, C., Farrington, J., Williams, F. \& Ashmore, F. (2017). The digital divide: Patterns, policy and scenarios for connecting the "final few" in rural communities across Great Britain. Journal of Rural Studies, 54, 386-398. DOI: 10.1016/j.jrurstud.2016.12.002.

[26] Riddlesden, D. \& Singleton, A. D. (2014). Broadband speed equity: A new digital divide? Applied Geography, 52, 25-33. DOI: 10.1016/j.apgeog.2014.04.008. 
[27] Rodríguez-Pose, A. (2018). The revenge of the places that don't matter (and what to do about it). Cambridge Journal of Regions, Economy and Society, 11(1), 189-209. DOI: $10.1093 /$ cjres/rsx024.

[28] Rosenthal, R. (1991). Meta-analytic Procedures for Social Research, 2nd ed. Newbury Park, CA: Sage.

[29] Selwyn, N. (2004). Reconsidering Political and Popular Understandings of the Digital Divide. New Media and Society, 6(3), 341-362. DOI: 10.1177/1461444804042519.

[30] Skerratt, S., Hall, C., Lamprinopoulou, C., McCracken, D., Midgley, A., Price, M., Renwick, A., Revoredo, C., Thomson, S., Williams, F. \& Wreford, A. (2010). Rural Scotland in Focus 2010, Edinburgh: Scottish Agricultural College.

[31] Talbot, H. and Gillespie, A. (2008). Policy and the rural Information Society. In Rusten, G. \& Skerratt, S., eds, Information and Communication Technologies in Rural Society: Being Rural in a Digital Age (pp. 155-174). Oxon: Routledge.

[32] van Dalen, H. P. \& Henkens, K. (2011). Who fears and who welcomes population decline? Demographic Research 25, 437-464. DOI: 10.4054/DemRes.2011.25.13.

[33] Van Dijk, J. (2005). The Deepening Divide: Inequality in the Information Society. London: Sage.

[34] van Dijk, J. (2012). The Network Society. London: Sage.

[35] Varga, A. (2017). Place-based, Spatially Blind, or Both? Challenges in Estimating the Impacts of Modern Development Policies: The Case of the GMR Policy Impact Modeling Approach. International Regional Science Review 40(1), 12-37. DOI: $10.1177 / 0160017615571587$.

[36] Wallace, C., Vincent, K., Luguzan, C. \& Talbot, H. (2015). Community Broadband Initiatives: What makes them successful and why? In Avram, G., de Ondo, F. \& Pipek, V., eds., Proceedings of the $7^{\text {th }}$ International Conference on Communities and Technologies (pp. 109-117). University of Limerick. DOI: 10.1145/2768545.2768548.

[37] Wallace, C., Vincent, K., Luguzan, C., Townsend, L. \& Beel, D. (2017). Information technology and social cohesion: a tale of two villages. Journal of Rural Studies 54, 426434. DOI: 10.1016/j.jrurstud.2016.06.005.

[38] Warren, M. (2007). The digital vicious cycle: links between social disadvantage and digital exclusion in rural areas. Telecommunications Policy, 31(6-7), 374-388. DOI: 10.1016/j.telpol.2007.04.001.

[39] Williams, F., Philip, L. J., Farrington, J. \& Fairhurst, G. (2016). "Digital by Default" and the "hard to reach': exploring solutions to digital exclusion in remote rural areas. Local Economy 31(7), 757-777. DOI: 10.1177/0269094216670938.

[40] Wilson, B., Atterton, J., Hart, J., Spencer, M. \& Thomson, S. (2018). Unlocking the digital potential of rural areas across the UK. London: Rural England.

[41] Wilson, R. \& Copus, A. (2018a). Services of General Interest (SGI) in the Scottish Sparsely Populated Area (SPA): Introduction, Classification by Delivery Mode, and Selection of Exemplar Services [Working paper]. Aberdeen: the James Hutton Institute.

[42] Wilson, R. \& Copus, A. (2018b). Services of General Interest (SGI) in the Scottish Sparsely Populated Area (SPA): Exemplar Services [Working paper]. Aberdeen: the James Hutton Institute.

[43] Wilson, R., Wallace, C. \& Farrington, J. (2015). A Virtual Geography of the Scottish Islands. Scottish Geographical Journal 131(3-4), 228-244. DOI: 10.1080/14702541.2015.1034761. 
[44] Audit Scotland (2018). Superfast broadband for Scotland: further progress update. Available:

http://www.audit-scotland.gov.uk/uploads/docs/report/2018/nr_180920_broadband.pdf (accessed 16 February 2019).

[45] Broadband for Scotland (2005). Broadband Connecting Scotland's Remote and Rural Communities. Available: http://broadbandforscotland.co.uk/archivenews3.html (accessed 16 February 2019).

[46] Comhairle nan Eilean Siar (2016) e-Sgoil. Available: http://www.e-sgoil.com/e-sgoilenglish-home/ (accessed 16 February 2019).

[47] ESPON EGTC (2017). Policy brief: Shrinking rural regions in Europe. Luxembourg: ESPON EGTC. Available:

https://www.espon.eu/sites/default/files/attachments/ESPON\%20Policy\%20Brief\%20on\%2 0Shrinking\%20Rural\%20Regions.pdf (accessed 3 October 2019).

[48] European Court of Auditors (2018). Special Report. Broadband in the EU Member States: despite progress, not all the Europe 2020 targets will be met. Luxembourg: European Court of Auditors. Available:

https://www.eca.europa.eu/Lists/ECADocuments/SR18_12/SR_BROADBAND_EN.pdf (accessed 25 January 2019).

[49] HIE (2014). Superfast subsea links ready to revolutionise digital way of life on Scottish islands. Available: http://news.hie.co.uk/all-news/superfast-subsea-links-ready-torevolutionise-digital-way-of-life-on-scottish-islands/ (accessed 16 February 2019).

[50] National Records of Scotland (2013). Geography - Background Information - Postcodes. Available: https://www.nrscotland.gov.uk/files//geography/products/postcode-bkgrd-info.pdf (accessed 25 January 2019).

[51] National Records of Scotland (2018a). Scottish Postcode Directory: Data Dictionary: 2018/2. Available: https://www.nrscotland.gov.uk/files//geography/2018-2/spddatadictionary-2018-2.pdf (accessed 24 January 2019).

[52] National Records of Scotland (2018b) News Bulletin. Scottish Postcode Directory 2018/2. Available: https://www.nrscotland.gov.uk/files//geography/2018-2/spd-newsbulletin-20182.pdf (accessed 1 February 2019).

[53] $\mathrm{NHS}$

Highland

(2018)

NHS

Near

Me.

https://www.nhshighland.scot.nhs.uk/NHSNEARME/Pages/Welcome.aspx 16 February 2019).

[54] Ofcom (2012c). UK Communications Infrastructure Report. Available: http://d2a9983j4okwzn.cloudfront.net/downloads/infrastructure-report-2012.pdf. (accessed 9 March 2014).

[55] Ofcom (2015). Connected Nations 2015: Full document. Available: https://www.ofcom.org.uk/_data/assets/pdf_file/0028/69634/connected_nations2015.pdf (accessed 30 January 2019).

[56] Ofcom (2016). Connected Nations 2016: Full document. Available: https://www.ofcom.org.uk/_data/assets/pdf_file/0035/95876/CN-Report-2016.pdf (accessed 30 January 2019).

[57] Ofcom (2017). Connected Nations 2017: Scotland. Available: https://www.ofcom.org.uk/_data/assets/pdf_file/0022/108814/scotland-connected-nations2017.pdf (accessed 30 January 2019).

[58] Ofcom (2018a). Connected Nations 2018: Annex A: Methodology section. Available: https://www.ofcom.org.uk/_data/assets/pdf_file/0033/129975/connected-nations-2018methodology.pdf (accessed 25 January 2019). 
[59] Ofcom (2018b). Connected Nations update: October 2018. Available: https://www.ofcom.org.uk/research-and-data/multi-sector-research/infrastructureresearch/connected-nations-update-2018-october (accessed 16 February 2019).

[60] Office of the Chief Statistician (2004). Scottish Neighbourhood Statistics Data Zones Background Information. Edinburgh: Scottish Executive. Available: https://www2.gov.scot/Resource/Doc/933/0120704.doc (accessed 25 January 2019).

[61] Point Topic (2012). Broadband coverage in Europe in 2011: Mapping progress towards the coverage objectives of the Digital Agenda. European Union. Available: https://algarve2020.eu/info/sites/algarve2020.eu/files/documentacao/Doc_Referencia/9._st udy_on_broadband_coverage_2011.pdf (accessed 25 January 2019).

[62] Scottish Executive (2001). Connecting Scotland: Our Broadband Future. Available: https://www2.gov.scot/Publications/2004/06/19531/39251 (accessed 16 February 2019).

[63] Scottish Executive (2006). A Study into Broadband Reach in Scotland. Available: https://www2.gov.scot/Resource/Doc/161597/0043878.pdf (accessed 16 February 2019).

[64] Scottish Government (2010). A Digital Ambition for Scotland. Available: https://www2.gov.scot/Publications/2010/10/Digital/Digital-Ambition (accessed 16 February 2019).

[65] Scottish Government (2011). Scotland's Digital Future: A Strategy for Scotland. Available: https://www.gov.scot/publications/scotlands-digital-future-strategy-scotland/pages/5/ (accessed 16 February 2019).

[66] Scottish Government (2016). Enhancing learning and teaching through the use of digital technology, https://www.gov.scot/publications/enhancing-learning-teaching-through-usedigital-technology/ (accessed 16 February 2019).

[67] Scottish Government (2017a). Reaching 100\%: superfast broadband for all. Available: https://www.gov.scot/publications/reaching-100-superfast-broadband/ $\quad$ (accessed 16 February 2019).

[68] Scottish Government (2017b). Realising Scotland's full potential in a digital world: a digital strategy for Scotland. Available: https://www.gov.scot/publications/realising-scotlands-fullpotential-digital-world-digital-strategy-scotland/ (accessed 16 February 2019).

[69] Scottish Government (2018). Scotland's Digital Health \& Care Strategy: Enabling, Connecting \& Empowering. Available: https://www.gov.scot/Resource/0053/00534657.pdf (accessed 16 February 2019).

[70] Scottish Government (2014). Scottish Government Urban/Rural Classification 2013-2014. Edinburgh: The Scottish Government. Available: https://www2.gov.scot/Resource/0046/00464780.pdf (accessed 30 January 2019).

[71] World Bank (2009). World Development Report 2009: Reshaping Economic Geography. Washington DC: The World Bank. Available:

http://documents.worldbank.org/curated/en/730971468139804495/pdf/437380REVISED01 BLIC1097808213760720.pdf (accessed 30 September 2019). 


\section{Appendix 1: Data sources}

The table below shows the postcode-level fixed broadband data used in the analysis. Although postcode-level data is available for 2014, the data on fixed broadband coverage were collected by Ofcom from three operators (BT, Virgin Media, and KCOM) (Ofcom, 2014: 176) only, while the 2015 coverage data includes additional information from five smaller broadband providers (Ofcom, 2015: 24, also see "About this data - Fixed postcode" notes ${ }^{3}$ ); the 2016-2018 reports and postcode datasets also include data from both large and small providers (Ofcom, 2016: 82; Ofcom, 2017: 31; Ofcom, 2018: 10; also see postcode data notes for these reports ${ }^{4}$ ).

\begin{tabular}{|l|l|l|}
\hline $\begin{array}{l}\text { Connected } \\
\text { Nations } \\
\text { Report }\end{array}$ & $\begin{array}{l}\text { Month of coverage } \\
\text { data }\end{array}$ & Download link \\
\hline 2015 & May 2015 & $\begin{array}{l}\text { http://www.ofcom.org.uk/static/research/connected- } \\
\text { nations2015/Fixed_Postcode_2015.zip }\end{array}$ \\
\hline 2016 & June 2016 & $\begin{array}{l}\text { https://www.ofcom.org.uk/static/research/connected- } \\
\text { nations2016/2016_fixed_pc_r01.zip }\end{array}$ \\
\hline 2017 & May 2017 & $\begin{array}{l}\text { https://www.ofcom.org.uk/static/research/connected- } \\
\text { nations2017/fixed-postcode-2017.zip }\end{array}$ \\
\hline 2018 & September 2018 & $\begin{array}{l}\text { https://www.ofcom.org.uk/_data/assets/file/0011/131042/201809_fix } \\
\text { ed_pc_r02.zip }\end{array}$ \\
\hline
\end{tabular}

Note that the month of coverage data collection was sourced from the notes accompanying the postcode data. Download links correct as of $27^{\text {th }}$ January 2019. Data: contains information licensed by the Office of Communications (Licence: https://www.ofcom.org.uk/research-and-data/multi-sectorresearch/infrastructure-research/connected-nations-2017/data-downloads/terms-of-use). 2018 data available under the Open Government Licence (https://www.nationalarchives.gov.uk/doc/opengovernment-licence/version/3/).

\section{Appendix 2: Postcode data analysis}

In a very small number of postcodes (e.g. 962 out of 1,625,141 in September 2018) the researcher-calculated proportion of premises with superfast coverage came to more than $100 \%$, possibly as a result of rounding in the raw data files. These figures were adjusted to $100 \%$.

Postcode coverage data were linked to Data Zones in Scotland using the Scottish Postcode Directory, a resource published by National Records of Scotland. The "Postcode Index" for the most recent version of this record (2018-2) was downloaded in January $2019^{5}$. This is a detailed dataset of postcode information, including the dates when postcodes were introduced (and, if applicable, deleted), and lookup information to a range of larger administrative and geographical areas for each postcode (National Records of Scotland, 2018a). All postcodes (Small User and Large User) within the Postcode Index were combined. As postcode boundaries change, and postcodes are created and deleted (National Records of Scotland, 2018a), the dates of introduction and deletion for each postcode were used to identify "valid" postcodes for the months when broadband data were collected by Ofcom. These subsets were then used to link the postcodes in the respective broadband data tables to Data Zones. The table below shows a summary of the link between postcode-level broadband data and Data

\footnotetext{
${ }^{3}$ See https://www.ofcom.org.uk/_data/assets/pdf_file/0029/77393/about_this_data_-_fixed_postcode.pdf (Accessed 27th January 2019)

4 2016: https://www.ofcom.org.uk/_data/assets/pdf_file/0029/97571/About-this-data-fixed-postcode-2016.pdf; 2017: https://www.ofcom.org.uk__data/assets/pdf_file/0028/108829/about-data-fixed-postcode-2017.pdf; 2018: https://www.ofcom.org.uk__data/assets/pdf_file/0013/131044/About-this-data-fixed-postcode-201809.pdf (Accessed 27th January 2019)

${ }^{5}$ National Records of Scotland 2018-2 Scottish Postcode Directory Files: Postcode Index - Comma Separated Value (CSV). Downloaded from https://www.nrscotland.gov.uk/files//geography/2018-2/spd-pc-index-cut-csv-18-2.zip. Contains NRS data (C) Crown copyright and database right 2019.
} 
Zones. The high level of spatial detail in the analysis is shown by the total number of broadband measurements, aggregated to almost 7,000 small areas in each of the four months.

\begin{tabular}{|l|l|l|l|l|}
\hline & May 2015 & June 2016 & May 2017 & September 2018 \\
\hline Total postcodes in analysis & 143,838 & 146,042 & 146,511 & 147,826 \\
\hline $\begin{array}{l}\text { Total Data Zones with linked } \\
\text { broadband data }\end{array}$ & 6,975 & 6,972 & 6,974 & 6,974 \\
\hline Number of linked postcodes per Data Zone: & 20.62 & 20.95 & 21.01 & 21.20 \\
\hline Mean & 10.42 & 10.86 & 10.85 & 11.17 \\
\hline Standard deviation & $1: 164$ & $1: 181$ & $1: 187$ & $1: 188$ \\
\hline Range (min:max) &
\end{tabular}

